University of Texas Rio Grande Valley

ScholarWorks @ UTRGV

Manufacturing \& Industrial Engineering Faculty

Publications and Presentations

College of Engineering and Computer Science

$11-2012$

\title{
Droplet Spray Behavior of an Atomization-Based Cutting Fluid (ACF) System for Machining of Titanium Alloys
}

Chandra Nath

Shiv G. Kapoor

Anil K. Srivastava

The University of Texas Rio Grande Valley

Jon Iverson

Follow this and additional works at: https://scholarworks.utrgv.edu/mie_fac

Part of the Industrial Engineering Commons, and the Manufacturing Commons

\section{Recommended Citation}

Nath, C, Kapoor, SG, Srivastava, AK, \& Iverson, J. "Droplet Spray Behavior of an Atomization-Based Cutting Fluid (ACF) System for Machining of Titanium Alloys." Proceedings of the ASME 2012 International Mechanical Engineering Congress and Exposition. Volume 3: Design, Materials and Manufacturing, Parts A, B, and C. Houston, Texas, USA. November 9-15, 2012. pp. 2023-2033. ASME. https://doi.org/10.1115/ IMECE2012-88369

This Conference Proceeding is brought to you for free and open access by the College of Engineering and Computer Science at ScholarWorks @ UTRGV. It has been accepted for inclusion in Manufacturing \& Industrial Engineering Faculty Publications and Presentations by an authorized administrator of ScholarWorks @ UTRGV. For more information, please contact justin.white@utrgv.edu, william.flores01@utrgv.edu. 


\section{DROPLET SPRAY BEHAVIOR OF AN ATOMIZATION-BASED CUTTING FLUID (ACF) SYSTEM FOR MACHINING OF TITANIUM ALLOYS}

\author{
Chandra Nath \\ University of Illinois at Urbana-Champaign \\ Urbana, IL, USA
}

\author{
Anil K. Srivastava \\ TechSolve Inc. \\ Cincinnati, OH, USA
}

\author{
Shiv G. Kapoor \\ University of Illinois at Urbana-Champaign \\ Urbana, IL, USA
}

\begin{abstract}
The aim of this research is to study droplet spray characteristics of an atomization-based cutting fluid (ACF) spray system including droplet entrainment angle and flow development regions with respect to three ACF spray parameters, viz., droplet and gas velocities, and spray distance. ACF spray experiments are performed by varying droplet and gas velocities. The flow development behavior is studied by modeling the droplets entrainment mechanism, and the density and distribution of the droplets across the jet flare. Machining experiments are also performed in order to understand the effect of the droplet spray behavior on the machining performances, viz., tool life/wear, and surface roughness during turning of a titanium alloy, Ti-6Al-4V. Experiments and the modeling of flow development behavior reveal that a higher droplet velocity and a smaller gas velocity result in smaller droplet entrainment angle leading to a gradual and early development of the co-flow with a smaller density and a better distribution of the droplet across the jet flare. Machining experiments also show that a higher droplet velocity, a lower gas velocity and a longer spray distance significantly improve the machining performances such as tool life and wear, and surface finish.

Key words: Titanium machining, Atomized droplets, Spray parameters, Co-flow jet, Machining performances.
\end{abstract}

\section{NOMENCLATURE}

$K_{x} \quad$ Proportionality constant

$N \quad$ Number of droplets

$P_{d} \quad$ Static pressure in the droplet nozzle

$P_{g s} \quad$ Static pressure of the gas at the jet center

$S_{d} \quad$ Spray distance measured from the gas nozzle exit

$U_{d}, U_{g}$ Droplet and gas velocities, respectively
$U_{g r} \quad$ Gas velocity at the outer contour of the gas jet

$U_{g s} \quad$ Droplet velocity due to static pressure drop

$U_{g x} \quad$ Local gas velocity

$U_{g} \quad$ Resultant velocity of a co-flowing droplet

$V_{N} \quad$ Control volume of the round nozzle

$V_{f} \quad$ Volumetric fluid flow rate

We Weber number

$K_{y} \quad$ Nondimensional group

$d_{g} \quad$ Exit diameter of the gas nozzle

$r_{j} \quad$ Local jet radius

$r_{p}, r_{i} \quad$ Radius at the near-field and intermediate field regions

$t \quad$ Time

$\theta_{r} \quad$ Droplet entrainment angle

$\theta_{j s} \quad$ Droplet entrainment angle due to static pressure drop

$\rho_{f} \quad$ Density of the cutting fluid

$\rho_{a} \quad$ Density of the atmospheric air

$\rho_{d} \quad$ Equivalent density of the droplet vapor

\section{INTRODUCTION}

Titanium alloys are being increasingly employed in a variety of engineering and biomedical applications due to their high specific strength, high-temperature strength, strong fracture and corrosion resistance, and biocompatibility. However, during machining of these alloys, high cutting zone temperature (above $500{ }^{\circ} \mathrm{C}$ ) localized in the vicinity of the cutting edge, and poor thermal conductivity and strong chemical affinity of titanium impose many constraints that accelerate tool wear [1-8].

Researchers have applied high-pressure cooling (HPC) and cryogenic cooling and observed tool life improvement over conventional flood cooling [2-9]; however, these processes do not offer the productivity by the same order due to significantly 
higher consumption of cutting fluid and/or energy [6-9]. Recently, Nath et al. [10] designed and evaluated an atomization-based cutting fluid (ACF) spray system for turning of a titanium alloy Ti-6Al-4V. By employing the ACF spray system, they observed an improvement in tool life of about 40$50 \%$ over flood cooling. A combination of spray system parameters including flow rate $(20 \mathrm{ml} / \mathrm{min})$, high-pressure gas ( 10.3 bar), spray distance (35 mm), impingement angle $\left(35^{\circ}\right)$, and air- $\mathrm{CO}_{2}$ gas mixture improved machining performances such as tool life, cutting force, and chip breakability. It was also seen that the air- $\mathrm{CO}_{2}$ mixture enhanced chip breakability due to its lower initial dispensing temperature. However, the effects of other ACF spray parameters were not deeply understood. While such an ACF spray system appears to be favorable, there is a lack of a physics-based understanding of the phenomena underlying the droplet spray behavior with respect to these ACF spray parameters.

In ACF spray system, two coaxial nozzles of different diameters are used for dispensing the droplets of cutting fluid towards the cutting zone [10-15]. Micro-size fluid droplets that are produced by an ultrasonic atomizer flow through the coaxial outer nozzle (named 'droplet nozzle') at a low velocity, and are entrained by the high-velocity gas flowing through the inner nozzle (called 'gas nozzle') to produce a focused axisymmetric droplet jet. During machining, the center of the ACF spray jet is directed towards the cutting region in order to obtain its maximum momentum, which is important for effective cooling and penetration at the tool-chip cutting interface. Therefore, the center of the jet has to be fully-developed with the droplets being distributed uniformly into the gas before it impinges at the cutting zone. The centerline mixing behavior with respect to the spray distance of such a co-flow spray jet can be influenced by the velocity of the droplet particles and the high-velocity gas that in turn influences the film formation behavior, and is likely to dominate machining performances. While the previous studies [16-19] provide valuable insight into co-flow spray jets produced from two gases, the velocity of the outer co-flow gas was not varied. Also, the entrainment mechanism of the outer gas into the inner gas was not studied. Rukosuyev et al. [11-12] observed droplet spray behavior such as focus height and length at different combinations of gas and droplet velocities for micromachining experiments. However, attention was not given to describe the flow development between the droplets and the gas due to entrainment/diffusion and the ACF spray parameters.

The objective of this research is to study droplet spray characteristics such as droplet entrainment zone and flow development regions with respect to three ACF spray parameters including droplet and gas velocities, and spray distance. In regard to this, ACF spray experiments are performed by varying droplet and gas velocities, and the droplet-gas flow development characteristics such as droplet density and distribution are observed with respect to spray distance. The flow development behavior for an ACF spray system is modeled in order to understand the entrainment mechanism of the droplets, and the density and distribution of the droplets across the jet flare. Machining experiments also are performed in order to understand the effect of the droplet spray behavior on the machining performances, viz., tool life/wear, and surface roughness during turning of Ti-6Al-4V.

The rest of the paper is organized as follows. Section 2 describes ACF spray experiments, and observations of the droplet entrainment angle, and density and distribution with respect to the ACF spray parameters. In Section 3, modeling of ACF droplet spray characteristics was presented in order to theoretically understand the droplet spray characteristics. Section 4 deals with setup and procedure for Ti-6Al-4V turning experiments, and the effect of droplet spray behavior on the machining performances. Section 5 draws conclusions based on the theoretical and the experimental findings.

\section{ACF SPRAY EXPERIMENTS}

The ACF spray experiments were conducted using the spray unit shown in Fig. 1. The system consists of: i) an ultrasonic vibration-based atomizer; ii) cutting fluid reservoir with a delivery tube; iii) nozzle unit; iv) high-pressure gas delivery nozzle/tube at the nozzle-spray unit; and v) four low-velocity air delivery tubes placed behind the atomizer tip. The atomizer (Model VC5040AT, Sonics and Materials, Inc.,) produces a mean droplet size of $50 \mu \mathrm{m}$ at the maximum flow rate of 166.67 $\mathrm{ml} / \mathrm{min}$. Once the fluid is atomized, the micro-size droplets move forward to the nozzle unit that consists of coaxial outer droplet and inner gas nozzles. The exit diameters of the droplet nozzle and the high-velocity gas nozzle are designed to be 18.8 $\mathrm{mm}$ and $1.6 \mathrm{~mm}$, respectively. Both nozzles are considered to have a convergence slope of $4^{\circ}$ and $0.75^{\circ}$, respectively, and the inner gas nozzle was placed $5 \mathrm{~mm}$ inside the droplet nozzle exit position in order to avoid divergence of droplets [10-12].

Experiments using a $2^{2}$ factorial design considering two droplet velocities and two gas velocities were performed to study the effects of droplet velocity and gas velocity on droplet spray characteristics including droplet entrainment zone (e.g. angle and distance) and flow development regions described by the droplet density and distribution. Droplet velocities were chosen to be 0.2 and $1.2 \mathrm{~m} / \mathrm{s}$. Note that, the droplets at a velocity of larger than $1.5 \mathrm{~m} / \mathrm{s}$ that are within the favorable range suggested by Rukosuyev et al. [11]. Gas velocities were selected to be 26 and $36 \mathrm{~m} / \mathrm{s}$ (10.3 bar and 20.6 bar, respectively, when measured by an anemometer). Spray distance, which is another ACF spray parameters in this study, will also be discussed in regard to flow development region. The fluid flow rate was chosen to be $20 \mathrm{ml} / \mathrm{min}$.

Figures 2(a)-(d) depict photographs of four different combinations of droplet velocity, $U_{d}$ and gas velocity, $U_{g}$ for an ACF spray system. The droplet entrainment angle, $\theta_{r}$, the direction at which the outer co-flow fluid droplets converge towards the center axis for conditions (a)-(d) are measured to be about $43.26^{\circ}, 24.44^{\circ}, 55.0^{\circ}$, and $29.05^{\circ}$, respectively. It is observed that when droplet velocity increases (conditions (a) vs. (b) or (c) vs. (d)), the droplet impingement angle, $\theta_{r}$ becomes 
smaller. A smaller value of $\theta_{\gamma}$ allows droplets to be entrained slowly with a comparatively longer downstream distance resulting in a larger droplet entrainment zone. Moreover, with the increase in gas velocity (conditions (a) vs. (c) or (b) vs. (d)), the droplet entrainment angle increases leading to a smaller droplet entrainment zone.

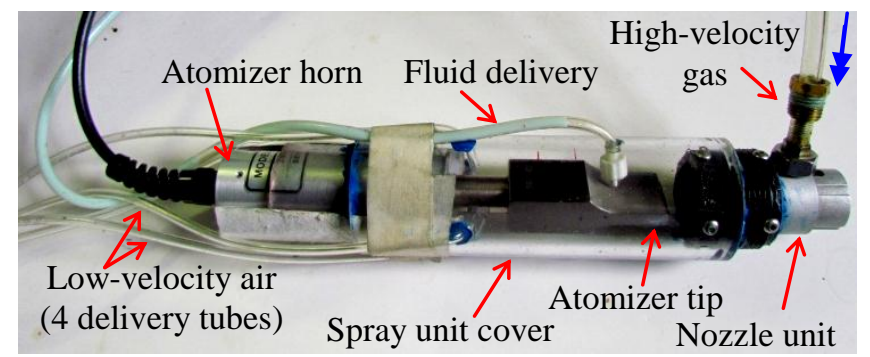

Figure 1 - Photograph of the ACF spray unit [10].

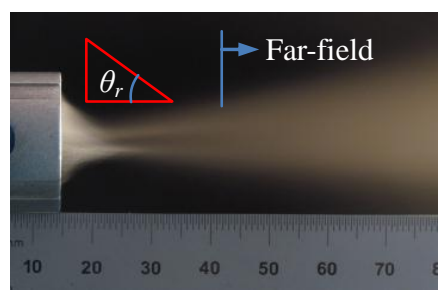

(a) $\theta_{r}=43.26^{\circ}, \mathrm{FF} \geq 32 \mathrm{~mm}$

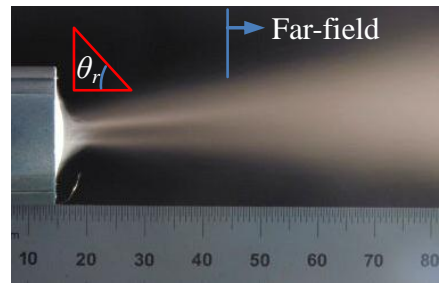

(c) $\theta_{r}=55.0^{\circ}, \mathrm{FF} \geq 35 \mathrm{~mm}$

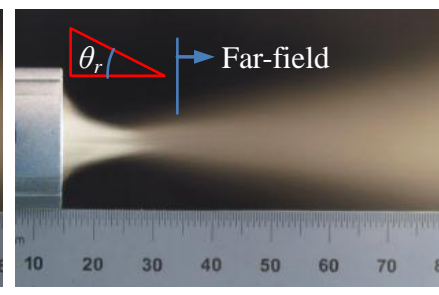

(b) $\theta_{r}=24.44^{\circ}, \mathrm{FF} \geq 24 \mathrm{~mm}$



(d) $\theta_{r}=29.05^{\circ}, \mathrm{FF} \geq 30 \mathrm{~mm}$
Figure - 2 Photographic images of ACF droplet-gas co-flow at: (a) $U_{d}=0.2 \mathrm{~m} / \mathrm{s}, U_{g}=26 \mathrm{~m} / \mathrm{s}$; (b) $U_{d}=1.2 \mathrm{~m} / \mathrm{s}, U_{g}=26$ $\mathrm{m} / \mathrm{s}$; (c) $U_{d}=0.2 \mathrm{~m} / \mathrm{s}, U_{g}=36 \mathrm{~m} / \mathrm{s}$; (d) $U_{d}=1.2 \mathrm{~m} / \mathrm{s}, U_{g}=36$ $\mathrm{m} / \mathrm{s}$ (scale: $\mathrm{mm}$; Gas nozzle exit is located at reading ' 10 ').

It can also be seen that each of the ACF spray conditions produces a droplet-free zone at the center of the nozzle. Depending on the spray condition, the droplet and the gas merge after a certain distance where the droplets are observed to be distributed uniformly across the jet flare. Photographic images provided by Rukosuyev et al. [11-12] also demonstrated a separation between the center gas jet and the droplet. Such a flow development behavior can be represented by a schematic diagram shown in Fig. 3. As seen in figure, as soon as the gas exits at the center, it entrains the surrounding fluid droplets creating a converging droplet entrainment zone around the gas nozzle for a certain distance. The resultant droplet-gas jet then diverges, but the mixing or flow development continues. The entire flow development region beginning from the gas nozzle exit point can be described by three distinct regions: nearfield (NF), intermediate-filed (IF), and far-field (FF). These are usually characterized by a normalized axial position, $x / d_{g}$, where $d_{g}$ is the exit diameter of the gas nozzle [20, 21]. Typical cross-sections A-A, B-B, and C-C of the jet flare at the NF, IF, and $\mathrm{FF}$ regions, respectively, are schematically illustrated in Fig. 3. In the NF region, a potential core is observed with absence of the outer co-flow medium. On the other hand, in the FF region, no potential core is observed as the mixing is fullydeveloped (i.e. 'self-similar' state) and hence, the droplets are uniformly distributed throughout the jet flare. The IF or transition region that lies between these two regions contains a few droplets as it approaches to the FF region. Note that the entrainment between the resultant jet and the ambient air at the outer contour can occur; however, this secondary entrainment is not discussed here because the droplet spray behavior at the center is of main interest during machining.

When considering a liquid dispensing into still ambient air or parallel moving air/gas, the authors in [20-21] found that the FF region is approximately $x / d_{g} \geq 25$. In this study, since the exit diameter of the inner gas nozzle is set $1.6 \mathrm{~mm}$, the selfsimilar state (i.e. distance between the gas nozzle exit and the FF region) is expected to fall at $40 \mathrm{~mm}$ or beyond. However, as seen in Figs. 2(a)-(d), the fully-developed or FF region is estimated to be in a range of approximately $24-35 \mathrm{~mm}$ for the conditions observed, which is smaller than the usual axisymmetric jet studies [20-21]. The early flow development of the self-similar state in the present study may be due to the fact that the density of the center gas (air) is lower than the outer co-flow gas (droplet). It is also observed from Figs. 2(a)(d) that when gas velocity decreases, the distance between the gas nozzle exit and the FF region becomes smaller. Thus the downstream distance for the self-similar state, where the flow becomes asymptotic, is smaller for a lower gas velocity. Similar observation was also reported in co-flow studies in [17].

From the above experiments, it is clear that droplet and gas velocities in an ACF spray system influence the droplet entrainment mechanism and the droplet-gas mixing behavior into the center jet. A combination of a higher droplet velocity $(1.2 \mathrm{~m} / \mathrm{s})$ and a lower gas velocity $(26 \mathrm{~m} / \mathrm{s})$, among four spray conditions observed, provide the best spray condition in term of droplet entrainment angle. Also, the self-similarity characteristic, which is relevant to the ACF spray distance, was observed to be formed earlier for this spray test than for the other three tests. The following section will present a model that describes how the three ACF spray parameters influence the flow development characteristics in an ACF spray system. Moreover, theoretical relationship of droplet and gas velocities with droplet entrainment angle and entrainment zone, and their influence on droplet density and distribution across the jet flare at three different regions (i.e. NF, IF, and FF) will be presented.

\section{MODELING OF ACF DROPLET SPRAY BEHAVIOR}

When a high-velocity fluid is dispensed into a still atmospheric air or to a low-velocity parallel moving fluid, 

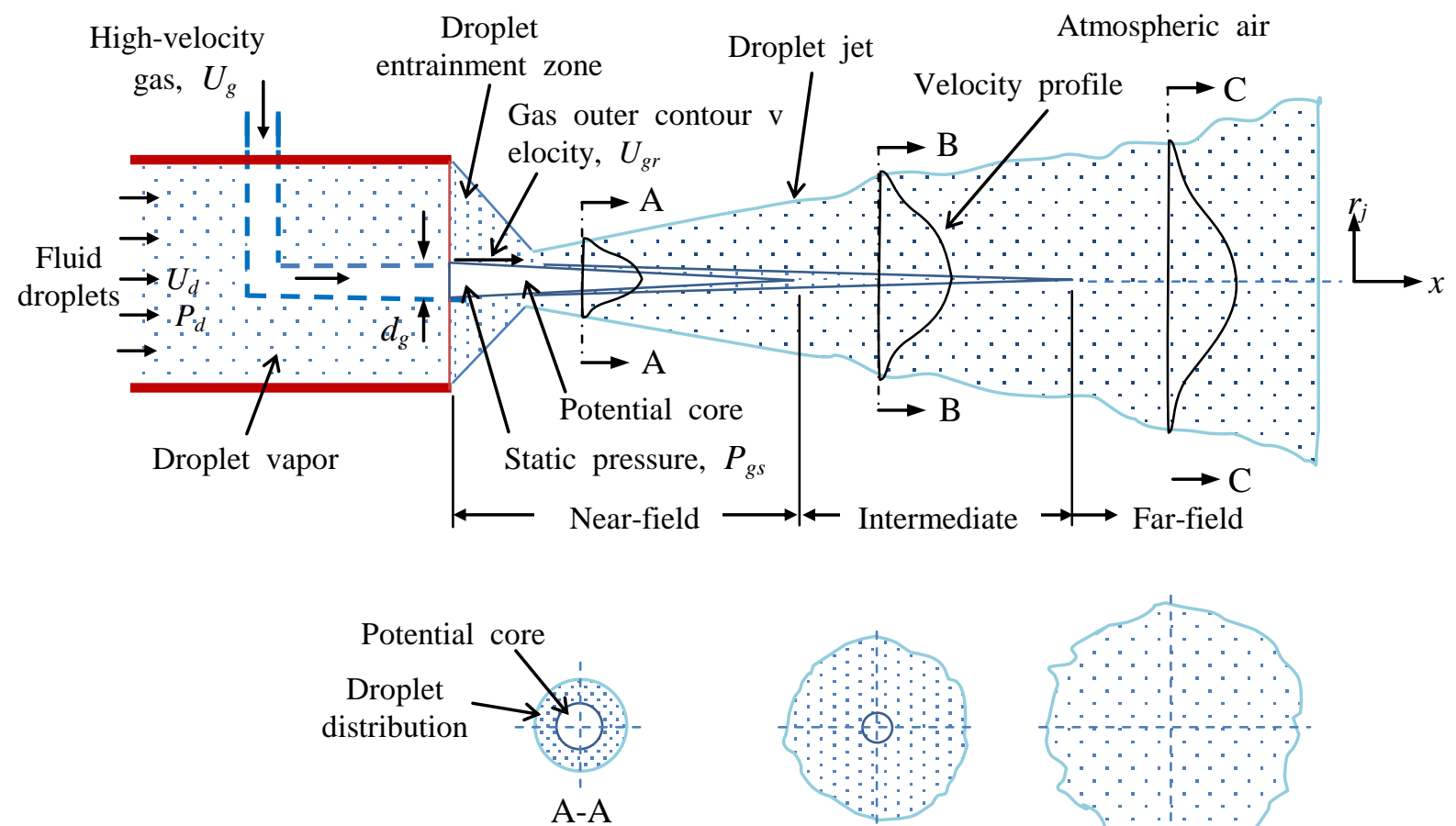

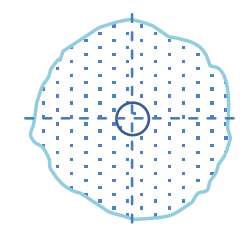

B-B

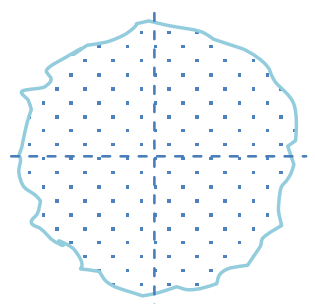

$\mathrm{C}-\mathrm{C}$

Figure - 3 Schematic of a typical axisymmetric co-flow jet produced by a high-velocity gas and fluid droplets, and its flow evolution regions with respect to downstream position. (A-A, B-B, and C-C denote cross-sections at three different regions).

entrainment of the outer fluid into the inner fluid takes place [16-23]. As the high-velocity fluid jet flows at a dynamic pressure, its static pressure reduces according to Bernoulli's principle [24]. This causes a pressure difference between the jet domain and the surrounding fluid/air. Moreover, if a compressible fluid like gas is dispensed (exit from a nozzle), it immediately expands in the radial direction. The pressure difference and the gaseous nature of the dispensing fluid cause entraining the outer surrounding gas or air to flow in and mix with the center gas. Due to differences in fluid properties and flow dynamics between the center jet and the outer droplets, one fluid diffuses into the other and vice versa. The slowmoving droplets cause aerodynamic drag to the high-velocity gas that results in deceleration of the gas, and the momentum lost by the high-velocity gas is received by the droplets [22]. Their momentum gradually evolves to an equilibrium state (i.e. fully-developed) as the jet moves forward. As a result, the velocity or dynamic pressure of the center jet, which is usually assumed to follow a Gaussian profile $[\mathbf{2 0}, \mathbf{2 3}, \mathbf{2 5}$ ], gradually decays with respect to the downstream position (Fig. 3).

In this section, the droplet entrainment angle with respect to droplet velocity, gas velocity, and the density and distribution of the droplets across the jet flare at three different flow development regions will be modeled. In order to estimate the droplet entrainment angle, the following assumptions are made about the nature of the droplets: i) Fluid droplets inside the droplet nozzle uniformly mix with the ambient air and create a homogenous droplet vapor. It appears to be a single gaseous phase, but different from the centerline gas jet in nature;

ii) Fluid droplets do not interact each other during flow (non-condensing);

iii) The fluid droplets are uniform in size;

iv) Gravitational force acting on the droplets is ignored.

\subsection{Droplet Entrainment Angle}

When a high-velocity gas is dispensed from a nozzle, the pressure difference between the jet and the surrounding rest or co-flow jet increases with the increase in its velocity. Gaussian mean velocity profile in Fig. 3 suggests that the velocity or dynamic pressure of the jet is the largest at the center producing to the least static pressure. In ACF spray system, the velocity of a static single droplet, $U_{g s}$ towards the jet center due to reduced static pressure can be calculated from Bernoulli's principle,

$$
P_{d}-P_{g s}=\frac{1}{2} \rho_{d} U_{g s}^{2} .
$$

where, $P_{d}, P_{g s}, P_{d}$ are static pressure of the droplets in the droplet nozzle, the static pressure of the gas at the jet center, droplet equivalent density of the droplet vapor, respectively. The pressure difference, $\left(P_{d}-P_{g g}\right)$ can be directly measured from a piezometer. The static pressure at the jet center, $P_{g s}$ decreases with an increase in gas velocity. For a given control 
volume consisting of a circular ACF nozzle unit (see Fig. 1), an equivalent density of the droplet vapor can be calculated using mass conservation law:

$$
\rho_{d}=\frac{\rho_{f} \bar{V}_{f} t+\rho_{a}\left(V_{N}-V_{f} t\right)}{V_{N}},
$$

where, $\rho_{f}$ and $\rho_{a}$ are the fluid and air density, $V_{f}$ is the volumetric fluid flow rate, $t$ is time, $V_{N}$ is the control volume in round nozzle.

Now, let a single droplet is entrained in the droplet entrainment zone, which is formed around the potential core immediately after the gas nozzle exit. When the droplet approaches to flow into the center at an angle, $\theta_{g s}$ due to the static pressure drop, the dynamic pressure of the jet that flows at a high velocity, $U_{g}$ pulls off the droplet in its flow direction at a velocity, $U_{g y}$ at the outer contour of the jet. The flow of the droplet due to the velocities, $U_{d}, U_{g s}$, and $U_{g y}$ can be represented by a velocity diagram illustrated in Fig. 4. The resultant droplet entrainment angle, $\theta_{r}$ of a co-flowing droplet can be expressed as:

$$
\theta_{y}=\tan ^{-1}\left(\frac{U_{g s}}{U_{d}+U_{g r}}\right) .
$$

where $U_{g y}$ is the velocity at the outer contour of the jet, and its value is obtained as:

$$
U_{g y}=k_{x} U_{g x}
$$

where, $k_{x}$ is a proportionality constant, and $U_{g x}$ is the local jet velocity in the $\mathrm{x}$-axis. At the nozzle exit, $x=0$, the value of $U_{g x}$ is approximately equal to $U_{g}$; however, it decreases with the increase in downstream distance as the velocity of the jet decays $[20,23,25]$. Also, for a compressible non-viscous fluid flow, $k_{x} \approx 1$ at $x=0$, because the velocity at the jet center is almost equal to the velocity at the outer contour $[\mathbf{2 1 , 2 6 ]}$.

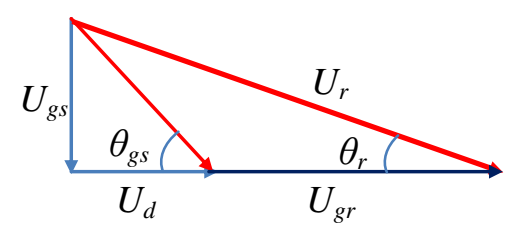

Figure - 4 A typical velocity diagram for a single droplet in the droplet entrainment zone $\left(U_{r}\right.$ : resultant velocity).

Equation 3 states that the droplet entrainment angle can be influenced by both gas velocity and droplet velocity. A higher droplet velocity, $U_{d}$ governs a droplet to follow at a smaller angle, $\theta_{r}$ with respect to the jet axis. However, the dependence of gas velocity, $U_{g}$ on the value of $\theta_{r}$ is a bit complex. With the increase in gas velocity, $U_{g}$, both the values of $U_{g y}$ and $U_{g s}$ increase. Note that, if the value of $U_{g}$ (or dynamic pressure) of the jet increases, the value of $U_{g s}$ also increases due to a comparatively larger static pressure drop, $\left(P_{d}-P_{g s}\right)$. Thus, it is hard to predict the influence of $U_{g}$ without knowing the value of the static pressure of the jet, $P_{g s}$.

The expression for the droplet entrainment angle, $\theta_{Y}$ in Eqn. (3) is obtained considering a single droplet in the droplet entrainment zone. However, when considering a number of droplets as ambient gas around the center jet, the droplet that is close to the gas jet contour will move faster than the one that is further away. Therefore, the value of $\theta_{r}$ estimated from the above relationships for a co-flow jet may not be accurate.

\subsection{Droplet Density and Distribution across Jet Flare}

As described in Section 2, the density and distribution of droplets across the jet flares at locations A, B, and C for three different regions: $\mathrm{NF}, \mathrm{IF}$ and $\mathrm{FF}$, respectively, are observed to be different (Fig. 3) due to gradual mixing between the droplets and the gas with respect to the downstream distance. Across the jet flare at cross-section A-A, the resultant jet of the droplets and the gas does not significantly diverge. Also, the diffusion between the droplets and the gas does not happen that much. As a potential core (i.e. no presence of the droplets) is distinctly observed at the center and the combined jet has a smaller outer contour, the number of droplets for a given volume (i.e. droplet density) becomes too high. On the other hand, across the jet flare at $\mathrm{C}-\mathrm{C}$, the diffusion is fully-developed, and the jet contains a larger contour because of divergence. As a result, the droplets uniformly distribute and the droplet density becomes smaller. At the cross-section B-B, the number of droplets across the jet flare may not be significant, but the size of potential core becomes smaller. If for the locations A, B, C, a small length, $\Delta \boldsymbol{x}$ is considered in both directions along $x$-axis, the average droplet density across the jet at the respective locations can be estimated as:

$$
\begin{aligned}
& \rho_{d A}=\frac{N}{2 \pi \Delta x\left(r_{j A}^{2}-r_{p A}^{2}\right)} \\
& \rho_{d B}=\frac{N}{2 \pi \Delta x\left(r_{j B}^{2}-r_{i B}^{2}\right)} \\
& \rho_{d C}=\frac{N}{2 \pi \Delta x r_{j C}^{2}} .
\end{aligned}
$$

where, $N$ is the number of fluid droplets depending on the flow rate and atomizer frequency, $r_{j A}, \gamma_{j B}, \gamma_{j C}$ are radii of the jet boundary layer at the locations A, B, C, respectively, and $r_{\mathrm{p} A}=r_{\mathbb{L} B}$ are radii of the potential core and the intermediate core at the locations, A, B, respectively. Note that the jet boundary layer suffers from an eddy (turbulence) effect due to 
entrainment of atmospheric air [20-23]. As such, average values of $r_{j B}$ and $r_{j c}$ should be taken for the intermediate and farfield regions. Eqns. 5(a)-(c) suggest that the average droplet density is significantly high at location A followed by medium at location $\mathrm{B}$, and the least at location $\mathrm{C}$.

\subsection{Condensation due to Multiple Fluid Droplets}

Developing the relationships for droplet density and distribution in Section 3.2, it was assumed that the droplet vapor that consists of air and droplets behave like one medium as a non-condensing gas. However, the fluid droplets may interact, especially when they come close or touch each other. This situation can take place in two ways: during entrainment in the droplet entrainment zone and during mixing within the NF (i.e. near-field) region. For a set of droplet and gas velocities, if the droplet entrainment angle increases, then the size droplet entrainment zone decreases due to a smaller downstream distance. In such a case, droplet density becomes higher that may lead to decrease in inter-droplet distance. If two or more droplets touch each other, they will result in condensation and will form, comparatively, a larger droplet. Also, during mixing within the NF region, the entire amount of droplets usually pass through a smaller jet flare (for example, at cross section A-A in Fig. 3) if the droplet entrainment angle increases. As the droplets again become closer, there is a higher chance of getting them closer that will lead to a condensation effect. If the droplet size becomes larger, it will influence film formation behavior $[10,15]$, and hence will affect the cooling and lubrication characteristics during machining.

In order to avoid condensation of the fluid droplets in the entrainment zone and next in the mixing region (i.e. near-filed and intermediate-field), it is preferable to allow the droplets to be entrained slowly and gradually until the intermediate region. In such a case, the radius of the jet at the NF and the IF regions will increase and the droplet density will decrease that will protect the fluid droplets from condensation. Figures 5(a)-(b) illustrate schematic diagrams for a smaller and a larger droplet impingement angles, respectively. A smaller droplet entrainment angle leads to increase the size of the droplet entrainment zone as well as the radius of the droplet-gas resultant jet, $r_{j}$. Using Eqn. (5a), it can be seen that the average droplet density for a larger value of $\theta_{r}$ (say, $\theta_{r 1}$ ) at the same location $A$ of the potential core will be higher than that for a smaller value of $\theta_{r}$ (say, $\theta_{r 2}$ ). That means, if $\theta_{r 1}>\theta_{r 2}$, then $\rho_{d 1}>\rho_{d 2}$ since $r_{j 1}<r_{j 2}$. This condition can be achieved by controlling the gas velocity and the droplet velocity that control the droplet entrainment angle (Eqn. (3)). Note that during machining with ACF spray system, the center of the jet is directed towards the cutting zone. As such, a fully-developed flow is required in order to produce a uniform fluid film for penetrating into the tool-chip interface. In Section 4, the machining experiments are conducted to understand the influence of the droplet spray behavior on the tool-chip interface and the resulting machining performances viz., tool life and wear, and surface roughness.
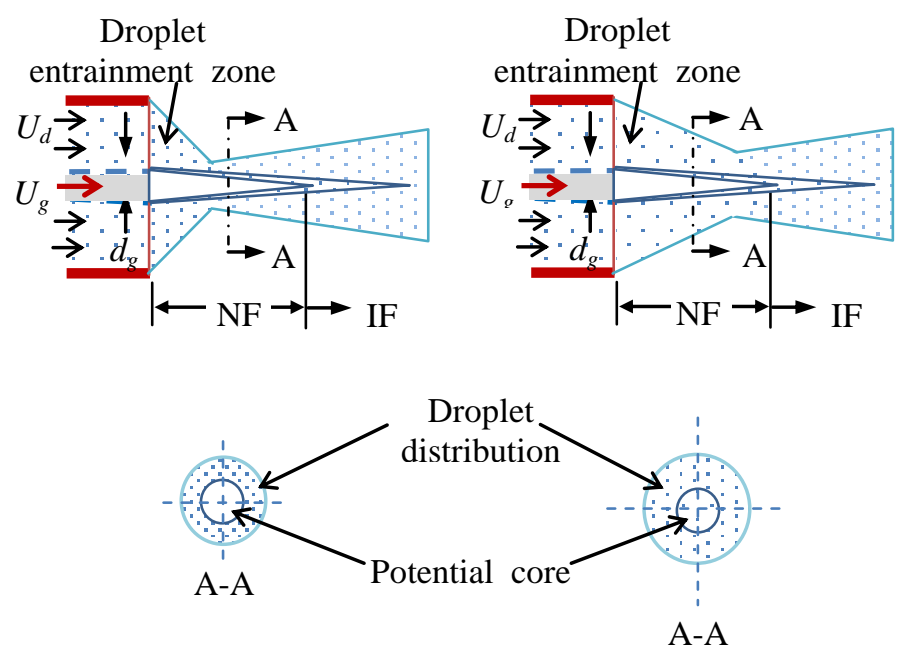

(a)

(b)

\begin{abstract}
Figure - 5 Variation of the droplet density across the jet flare at the same location A for: (a) smaller; and (b) larger droplet entrainment angles.
\end{abstract}

\section{TI-6AL-4V TURNING EXPERIMENTS 4.1 Experimental Setup and Design}

A schematic of an ACF spray system setup for turning operation is shown in Fig. 6(a). A Mori Seiki Frontier L-1 CNC lathe was used for turning experiments as depicted in Fig. 6(b). A cylindrical Ti-6Al-4V bar of size $\varnothing 175 \mathrm{~mm}$ x $325 \mathrm{~mm}$ was used for turning. Uncoated microcrystalline carbide inserts ISO grade K313 from Kennametal was used as tool material and placed on a standard Kennametal shank. The tool geometry was set as follows: $5^{\circ}$ rake angle, $11^{\circ}$ clearance angle, $60^{\circ}$ major cutting edge angle, $0.8 \mathrm{~mm}$ nose radius. The tool shank was secured with a Kistler 3-component force dynamometer (type 9121) to capture the cutting force data through a National Instrument data acquisition system (SCB-68) integrated with the LabVIEW software. The cutting conditions were selected to be $80 \mathrm{~m} / \mathrm{min}$ cutting speed, $0.2 \mathrm{~mm} / \mathrm{rev}$ feed rate, and $1 \mathrm{~mm}$ depth of cut [2-8]. Water-soluble cutting fluid S-1001 at 10\% dilution was used as coolant at a flow rate of $20 \mathrm{ml} / \mathrm{min}$. The thermo-physical properties of $10 \% \mathrm{~S}-1001$ is as follows: density $1003 \mathrm{~kg} / \mathrm{m}^{3}$, surface tension $41 \mathrm{mN} / \mathrm{m}$, viscosity $1.22 \mathrm{cP}$, and thermal conductivity $0.53 \mathrm{~W} / \mathrm{m}-\mathrm{K}$.

The ACF spray unit shown in Fig. 1 was used in the present study. The unit was placed inside the machine on a metal frame that is fastened with the lathe turret. The frame allows the ACF spray unit to be adjusted at a desired impingement angle, orientation, and spray and spot distances. The spray unit was directed on the tool rake face and its centerline was oriented along the major cutting edge (i.e. $60^{\circ}$ with the work axis) for impinging the droplets in the direction of the cutting edge. The spot distance (see Fig. 1) is set about $8 \mathrm{~mm}$. As a train of droplets impinged, a fluid film continuously produces and moves forward that penetrates into the tool-chip interface. Before impinging on the rake face, the distribution and the 
density of the droplets across the jet flare at different axial position of the jet are influenced by three system parameters, viz., gas velocity, atomized droplets velocity, and spray distance. A replicated $2^{3}$ full factorial design was used in conducting experiments as seen in Table 1 . The gas velocity was chosen to be $26 \mathrm{~m} / \mathrm{s}$ and $36 \mathrm{~m} / \mathrm{s}$ (measured by a handheld digital anemometer (from Omega) at 10.3 bar at 20.6 bar, respectively), and the impingement angle was chosen to be $35^{\circ}$ so that the spreading regime (nondimensional Weber number, We $\geq 10$ and group, $K_{y} \leq 17$ ) occurs on the rake face [13]. Air$\mathrm{CO}_{2}$ mixture was used as the high-velocity gas for controlling a lower initial dispensing temperature of about $1-2{ }^{\circ} \mathrm{C}[\mathbf{1 0}]$.

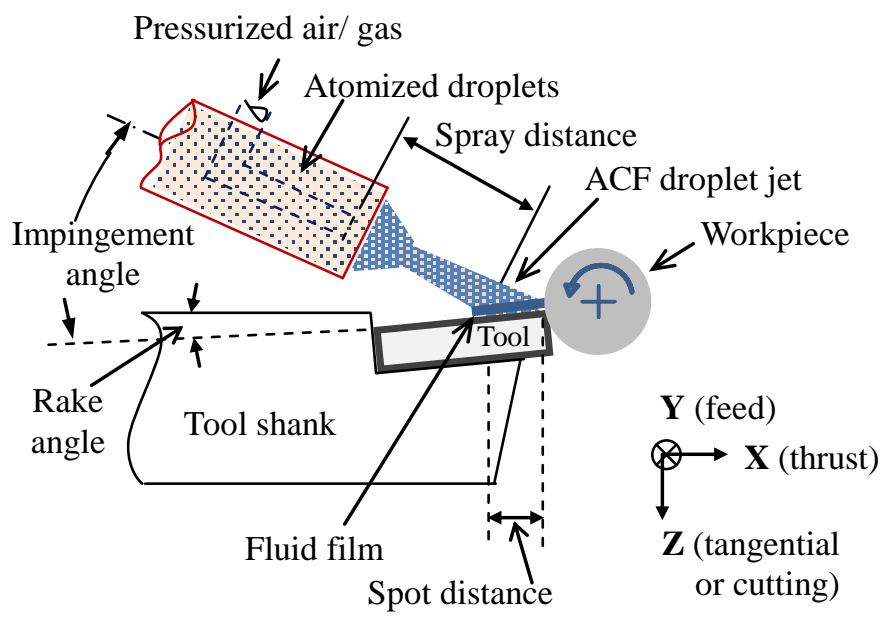

(a)

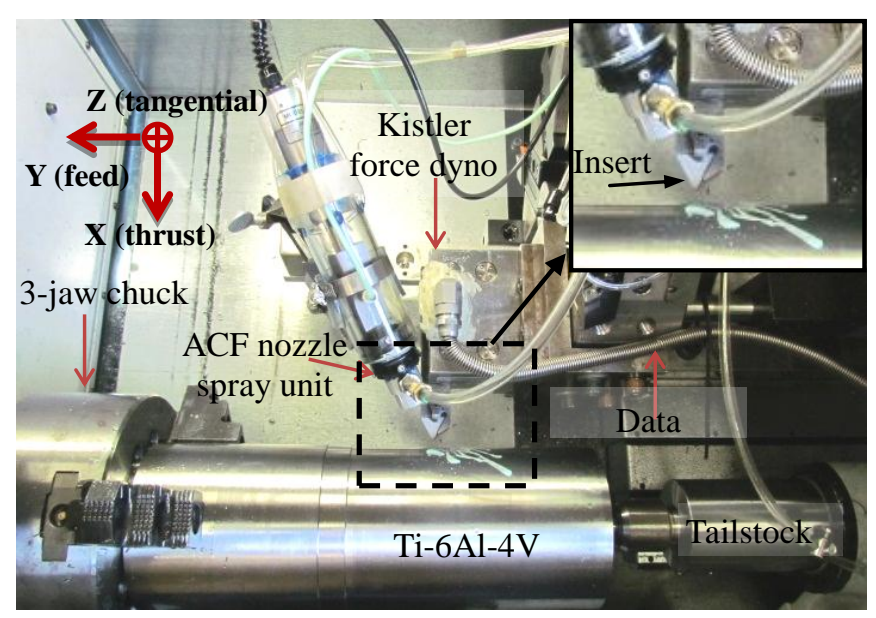

(b)

Figure 6 - (a) ACF spray parameters in turning setup; (b) Experimental setup with the ACF spray system in a CNC lathe (inset: cutting insert).

For all the cutting conditions, the tools were removed from the setup first at $4 \mathrm{~min}$ and then at 6 min to observe the progress of wear. The tool thereafter was checked every one minute until the maximum flank wear land reached $0.6 \mathrm{~mm}$ according to the
ISO standard. The maximum tool flank wear was measured using a Quadra-Check 300 optical microscope. Average and maximum surface roughness $\left(R_{a}\right.$ and $R_{z}$, respectively) values were measured using a portable roughness tester $T R 100$. The surface roughness was measured starting at $1 \mathrm{~min}$ with an interval of 2 min until the tool survives.

Table 1 Factor levels for the ACF spray parameters.

\begin{tabular}{l|c|c}
\hline Parameters & Low $(-)$ & High $(+)$ \\
\hline$\left(x_{1}\right)$ Droplet velocity, $U_{\mathbb{d}}(\mathrm{m} / \mathrm{s})$ & 0.2 & 1.2 \\
\hline$\left(x_{2}\right)$ Gas velocity, $U_{g}(\mathrm{~m} / \mathrm{s})$ & 26 & 36 \\
\hline$\left(x_{3}\right)$ Spray distance, $S_{d}(\mathrm{~mm})$ & 25 & 35 \\
\hline
\end{tabular}

\subsection{Results of the Turning Experiments}

In this section, the experimental results of the effects of the ACF spray parameters, viz., droplet velocity, gas velocity, and spray distance on the machining performances including tool life/wear, and surface roughness are presented.

\subsubsection{Tool Life and Wear}

Turning tests on Ti-6Al-4V were performed using the ACF spray system for the conditions listed in Table 1. Table 2 depicts tool life for two repeated test runs and their average value for each set of ACF spray conditions. An analysis at 95\% confidence interval show that the tool life is significantly influenced by all three spray parameters such as spray distance, droplet velocity, and gas velocity. With the increase in spray distance and droplet velocity, and the decrease in gas velocity, regardless of varying them individually or together, the tool life can undoubtedly be improved during titanium machining.

Table 2 - Tool life at different ACF spray conditions.

\begin{tabular}{c|c|c|c|c|c|c}
\hline \multirow{2}{*}{$\begin{array}{c}\text { Test } \\
\text { no. }\end{array}$} & \multicolumn{2}{|c|}{ Parameters } & \multicolumn{3}{c}{ Tool life (min) } \\
\cline { 2 - 7 } & $\boldsymbol{x}_{\boldsymbol{1}}$ & $\boldsymbol{x}_{\boldsymbol{2}}$ & $\boldsymbol{x}_{\boldsymbol{3}}$ & Run 1 & Run 2 & Average \\
\hline 1 & 0.2 & 26 & 25 & 7 & 7 & 7 \\
\hline 2 & 1.2 & 26 & 25 & 8 & 8 & 8 \\
\hline 3 & 0.2 & 36 & 25 & 7 & 8 & 7.5 \\
\hline 4 & 1.2 & 36 & 25 & 8 & 7 & 7.5 \\
\hline 5 & 0.2 & 26 & 35 & 9 & 8 & 8.5 \\
\hline 6 & 1.2 & 26 & 35 & 10 & 11 & 10.5 \\
\hline 7 & 0.2 & 36 & 35 & 9 & 8 & 8.5 \\
\hline 8 & 1.2 & 36 & 35 & 10 & 9 & 9.5 \\
\hline
\end{tabular}

The effect of spray distance, $S_{d}$ on tool life can be observed by typical wear of the tool rake and flank shown in Figures 7 and 8 for Test nos. 2 and 6, respectively, where the values of droplet and gas velocities are kept constant $\left(U_{\mathbb{d}}: 1.2\right.$ $\left.\mathrm{m} / \mathrm{s}, V_{g}: 26 \mathrm{~m} / \mathrm{s}\right)$. It is seen that when spray distance, $S_{d}$ 
increases from 25 to $35 \mathrm{~mm}$, the tool survives for longer time. The maximum tool flank wear widths for these two tests are measured to be about 0.193 and $0.153 \mu \mathrm{m}$ at $4 \mathrm{~min}, 0.721$ and $0.453 \mu \mathrm{m}$ at $8 \mathrm{~min}$ cutting, respectively. Also, an improved tool rake face condition can be observed for $35 \mathrm{~mm}$ as compared to that for $25 \mathrm{~mm}$ spray distance.

The tool life improvement at $35 \mathrm{~mm}$ spray distance is due to the fact that, the droplets-gas co-flow is fully-developed (i.e. in the FF region) in all the ACF conditions tested in Figs. 2(a)-(d). The fluid droplets across the jet flare are distributed uniformly across the jet flare, as seen in Fig. 3. As such, an even and thicker fluid film continuously forms that leads to a better cooling and lubrication effect at the tool-chip cutting interface. Since the center of the spray jet is directed towards the cutting zone during turning, this fluid film results in longer tool life. In contrast, since the fluid droplets at the center of the jet before the FF region are comparatively less, the resultant fluid film becomes uneven and much thinner. Such a fluid film may not provide enough cooling and lubrication effects, and thus cause
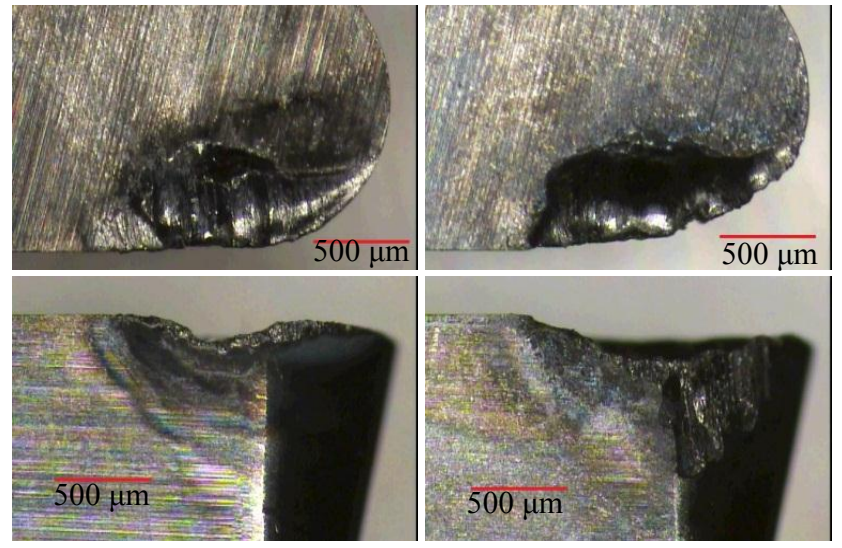

(a) at 4 min

(b) at $8 \mathrm{~min}$

Figure - 7 Photographs of tool rake and flank faces for Test no. $2\left(U_{d}: 1.2 \mathrm{~m} / \mathrm{s}, U_{g}: 26 \mathrm{~m} / \mathrm{s}, S_{d}: 25 \mathrm{~mm}\right)$.


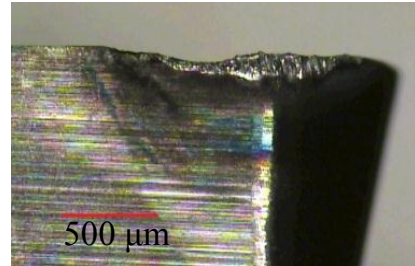

(a) at $4 \mathrm{~min}$

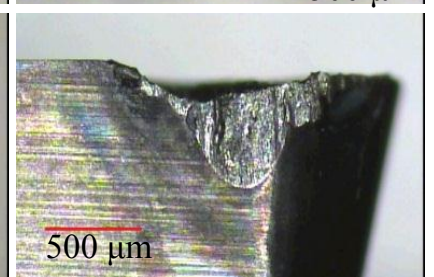

(b) at $7 \mathrm{~min}$
Figure - 9 Photographs of tool rake and flank faces for Test no. $1\left(U_{d}: 0.2 \mathrm{~m} / \mathrm{s}, U_{g}: 26 \mathrm{~m} / \mathrm{s}, S_{d}: 25 \mathrm{~mm}\right)$. increased tool wear.

The effect of variation of droplet velocity from 0.2 to 1.2 $\mathrm{m} / \mathrm{s}$ can be observed by images of tool rake and flank wear in Figs. 7 and 9, for example, where gas velocity $(26 \mathrm{~m} / \mathrm{s})$ and spray distance $(25 \mathrm{~mm})$ are kept fixed. It is found that the tool wear decreased with the increase in droplet velocity. According to Eqn. (3), if droplet velocity, $U_{d}$ increases, the droplet entrainment angle, $\theta_{r}$ becomes smaller. Also, as seen in ACF spray experiment in Figs. 2(a)-(b), if droplet velocity increases from 0.2 to $1.2 \mathrm{~m} / \mathrm{s}$ at the same gas velocity of $26 \mathrm{~m} / \mathrm{s}$, the value of $\theta_{r}$ decreases from $43.26^{\circ}$ to $24.44^{\circ}$. Similar trend is observed in Figs. 2(c)-(d) at another gas velocity of $36 \mathrm{~m} / \mathrm{s}$. A smaller value of $\theta_{r}$ allows gradual mixing or diffusion of the droplets into the gas jet. As a result, the droplet density becomes lower (see Eqns. 5(a)-(c)) and condensation between the droplets can be avoided (see Section 3.3). Also, this condition helps in early development of the FF region (in Fig. 2(b)) that helps in achieving an improved tool life as compared to the other conditions.

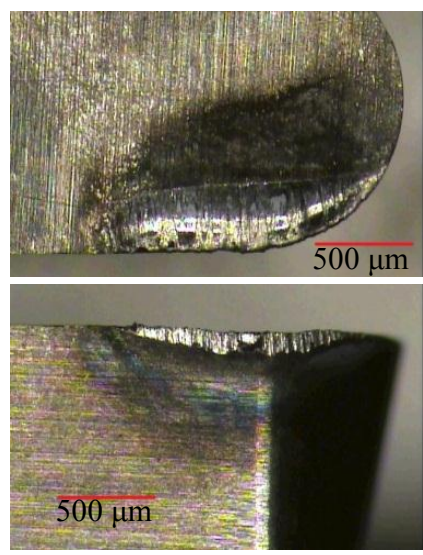

(a) at 4 min
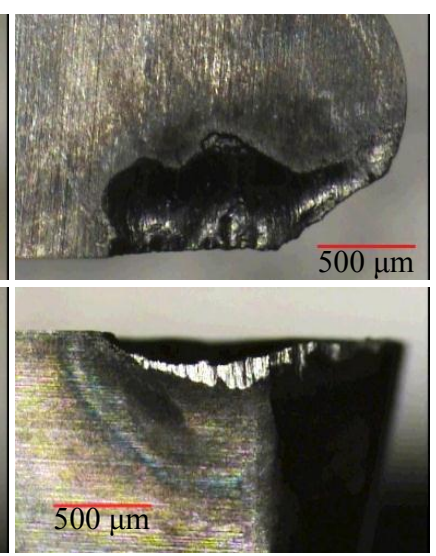

(b) at $8 \mathrm{~min}$
Figure - 8 Photographs of tool rake and flank faces for Test no. $6\left(U_{d}: 1.2 \mathrm{~m} / \mathrm{s}, U_{g}: 26 \mathrm{~m} / \mathrm{s}, S_{d}: 35 \mathrm{~mm}\right)$.
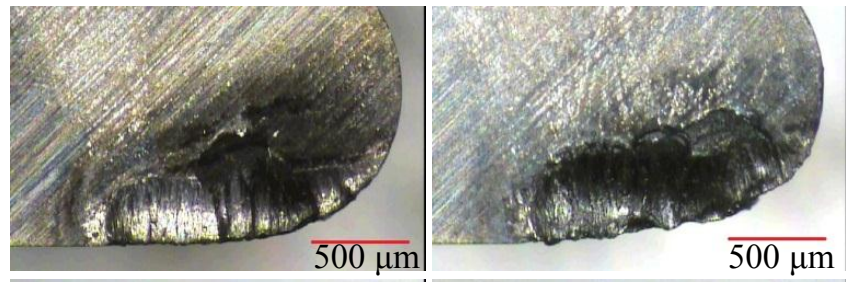

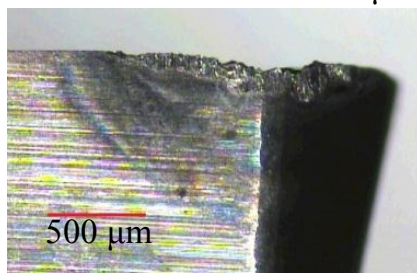

(a) at $4 \mathrm{~min}$

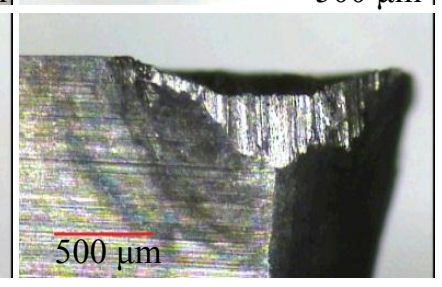

(b) at $8 \mathrm{~min}$
Figure - 10 Photographs of tool rake and flank faces for Test no. $8\left(U_{d}: 1.2 \mathrm{~m} / \mathrm{s}, U_{g}: 36 \mathrm{~m} / \mathrm{s}, S_{d}: 35 \mathrm{~mm}\right)$. 
Figures 8 and 10 show images of tool rake and flank faces at different gas velocities for Test nos. $6\left(U_{g}: 26 \mathrm{~m} / \mathrm{s}\right)$ and $8\left(U_{g}\right.$ : $36 \mathrm{~m} / \mathrm{s})$, where droplet velocity $(1.2 \mathrm{~m} / \mathrm{s})$ and spray distance $(35$ $\mathrm{mm})$ are kept constant. With the increase in gas velocity, the tool life shortens. From the ACF spray experiments in Figs. 2(a) and (c), it is found that with the increase in gas velocity from 26 to $36 \mathrm{~m} / \mathrm{s}$ at the same droplet velocity of $1.2 \mathrm{~m} / \mathrm{s}$, the value of $\theta_{y}$ increases from $43.26^{\circ}$ to $55.0^{\circ}$. Figures 2(b) and (d) also show similar trend. This reveals that a larger gas velocity results in larger droplet entrainment angle, $\theta_{y}$. As a result, the droplet density and distribution change in a way that it adversely influences tool life (Test nos. 6 and 8).

In summary, a larger spray distance $(35 \mathrm{~mm})$, a higher droplet velocity $(1.2 \mathrm{~m} / \mathrm{s})$, and a smaller gas velocity $(26 \mathrm{~m} / \mathrm{s})$ enhances tool life by reducing tool wear in titanium machining.

\subsubsection{Surface Roughness}

Figures 11(a) and (b) present the average and maximum roughness values at different cutting intervals for the conditions under the same Test nos. 1, 2, 6, and 8 that were discussed in Section 4.2.1. It is observed that the surface degraded as the tool wear progresses with the cutting time. However, depending on the ACF spray conditions, the roughness values become different after 3 min cutting time. With the increase in spray distance and droplet velocity, and the decrease in gas velocity, the increment in surface roughness values is gradual and found to be comparatively smaller. The tool in Test no. 6 operated at a larger spray distance $(35 \mathrm{~mm})$, a higher droplet velocity $(1.2$ $\mathrm{m} / \mathrm{s})$, and a lower gas velocity $(26 \mathrm{~m} / \mathrm{s})$ offered improved surface roughness compared to the other three tests. In contrast, the roughness values in Test no. 1, which is conducted at $25 \mathrm{~mm}$ spray distance, $0.2 \mathrm{~m} / \mathrm{s}$ droplet velocity, and $36 \mathrm{~m} / \mathrm{s}$ gas velocity, increases at a considerably higher rate. This finding is in agreement with the earlier observations on tool life and wear.

In order to understand the effect of the spray behavior on

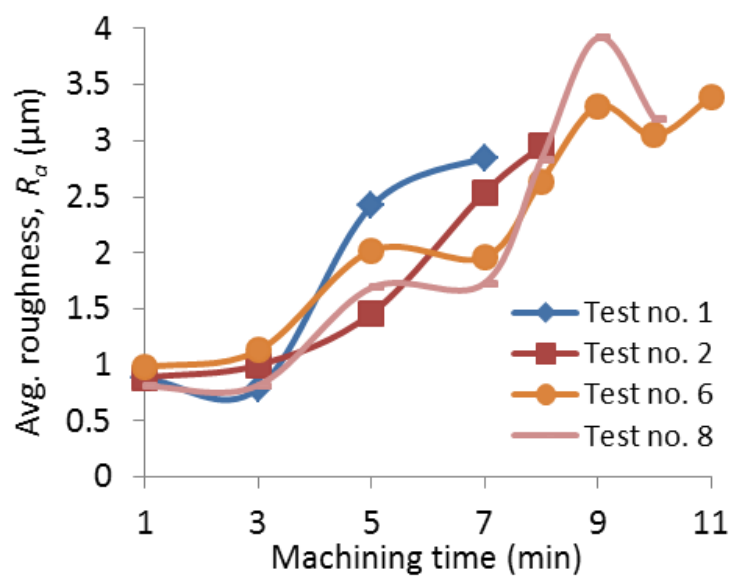

(a) both tool wear and surface finish, the three cutting force components, viz., tangential, feed and thrust forces were collected. Table 3 presents the values of these force components and their resultant cutting force at different cutting intervals until the tool life for Test nos. 1, 2, 6 and 8 (refer to Table 2 and Figs. 7-10). Also, in order to understand the penetration and lubrication effect of ACF spray-produced thin film at the toolchip cutting interface, cutting force data at these intervals are represented in terms of friction coefficient. Figure 12 presents values of friction coefficient, $\mu$ that is calculated using the following expression [7],

$$
\mu=\frac{F_{z} \sin \emptyset \tan \gamma_{0}+F_{y} \cos \gamma_{0}}{F_{z} \sin \emptyset \cos \gamma_{0}-F_{y} \sin \gamma_{0}}
$$

where, $F_{y}, F_{z}, \emptyset, \gamma_{0}$ are feed force, tangential cutting force, principle cutting edge angle, and orthogonal rake angle, respectively.

When increasing spray distance from 25 to $35 \mathrm{~mm}$ (Test nos. 2 and 6 , respectively) with other two spray parameters remain constant, the values of the cutting forces and the friction coefficient are found to be comparatively lower. This is because, at a spray distance of $35 \mathrm{~mm}$, the fluid droplets are found to be distributed uniformly across the jet flare (see Figs. 2(a)-(d)). This causes to forming an even and uniform fluid film that helps in penetrating into the tool-chip cutting interface. This helps in achieving a better cooling and lubrication effect, and thus enhances tool life and surface roughness in this spray condition. In contrast, at a smaller spray distance, the dropletsgas co-flow is not fully developed. The number of fluid droplets is less in the center of the flow. As a result, the resulting film becomes thin and uneven. Also the interface did not receive sufficient cooling and lubrication effect, and hence accelerated tool wear and degraded surface finish.

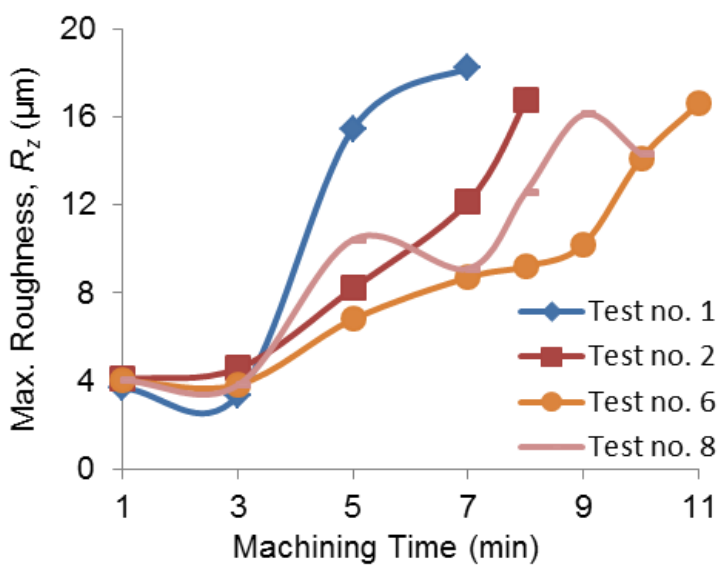

(b)

Figure - 11 (a) Average surface roughness, $R_{a}$; and (b) maximum surface roughness, $R_{z}$ values at different machining times for different spray conditions. 
Table -3 Cutting forces for various tests at different cutting intervals during turning of Ti-6Al-4V.

\begin{tabular}{|c|c|c|c|c|c|c|c|c|c|}
\hline \multirow{2}{*}{ Test no. } & \multirow[t]{2}{*}{ Forces $(\mathbf{N})$} & \multicolumn{8}{|c|}{ Machining time (min) } \\
\hline & & 1 & 3 & 5 & 7 & 8 & 9 & 10 & 11 \\
\hline \multirow{4}{*}{1} & Thrust $\left(F_{x}\right)$ & 125.81 & 133.50 & 357.58 & 771.68 & & & & \\
\hline & Feed $\left(F_{y}\right)$ & 136.66 & 149.45 & 348.21 & 592.23 & & & & \\
\hline & Tangential $\left(F_{z}\right)$ & 437.17 & 455.34 & 572.72 & 685.63 & & & & \\
\hline & Resultant & 475.01 & 497.49 & 759.69 & 1190.09 & & & & \\
\hline \multirow{4}{*}{2} & Thrust $\left(F_{x}\right)$ & 126.95 & 128.82 & 173.39 & 331.58 & 971.54 & & & \\
\hline & Feed $\left(F_{y}\right)$ & 138.42 & 140.73 & 155.46 & 396.13 & 886.08 & & & \\
\hline & Tangential $\left(F_{z}\right)$ & 428.55 & 443.13 & 457.88 & 554.42 & 751.57 & & & \\
\hline & Resultant & 467.90 & 442.45 & 513.70 & 757.79 & 1502.95 & & & \\
\hline \multirow{4}{*}{6} & Thrust $\left(F_{x}\right)$ & 126.52 & 135.02 & 191.64 & 198.26 & 205.71 & 228.68 & 264.13 & 297.21 \\
\hline & Feed $\left(F_{y}\right)$ & 131.68 & 168.34 & 193.10 & 200.2 & 210.03 & 207.45 & 224.09 & 278.12 \\
\hline & Tangential $\left(F_{z}\right)$ & 430.97 & 462.22 & 481.93 & 503.65 & 524.67 & 520.00 & 541.40 & 596.60 \\
\hline & Resultant & 468.06 & 510.12 & 553.42 & 577.10 & 601.42 & 604.76 & 642.72 & 722.23 \\
\hline \multirow{4}{*}{8} & Thrust $\left(F_{x}\right)$ & 106.70 & 157.88 & 236.21 & 278.05 & 390.71 & 444.47 & 447.56 & \\
\hline & Feed $\left(F_{y}\right)$ & 125.27 & 215.94 & 243.57 & 275.36 & 343.56 & 439.73 & 464.63 & \\
\hline & Tangential $\left(F_{z}\right)$ & 426.70 & 442.11 & 534.82 & 556.20 & 597.32 & 649.87 & 680.72 & \\
\hline & Resultant & 457.33 & 516.74 & 633.37 & 680.07 & 792.14 & 901.80 & 937.86 & \\
\hline
\end{tabular}

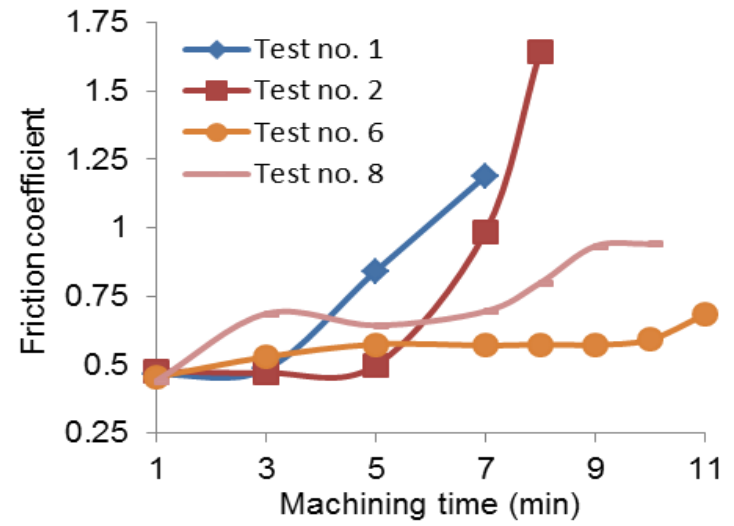

Figure - 12 Friction coefficient values at different machining times for different ACF spray conditions.

The effect of droplet velocity on the cutting forces and the friction coefficient can also be seen in Table 3 and Fig. 12, respectively, when comparing Test nos. 1 and 2 . If the droplets are pushed from behind the atomizer tip (Fig. 1) at a higher velocity of $1.2 \mathrm{~m} / \mathrm{s}$ compared to $0.2 \mathrm{~m} / \mathrm{s}$, these performances are found to be improved. This is due to the following reason. With the increase in droplet velocity, the droplet entrainment angle decreases (Eqn. (3)), which allows gradual development of the droplets and the gas and helps in avoiding droplet condensation effect (see Section 3). As a result, the cutting interface receives an effective cooling and lubrication effect, and therefore results in lower cutting force and friction coefficient.

When comparing Test nos. 6 and 8 for studying the effect of gas velocity, it is observed that a lower gas velocity offers lower cutting force and a smaller friction coefficient, as depicted in
Table 3 and Fig. 12. As seen in ACF spray experiment in Figs. 2(a)-(d), when gas velocity decreases, the droplet entrainment angle also decreases that again helps in obtaining lower cutting forces and lower friction coefficient.

It is interestingly observed that both the values of cutting force and friction coefficient appear to be close in first few minutes of cutting, say, 2-4 min. However, as the cutting progresses, the tool wear behavior changes, which responds to cutting forces and friction coefficient accordingly. It is because, in the beginning of cutting, a fresh tool can survive for some time with smaller increase in cutting force and friction coefficient values. However, the tool-chip cutting interface after 2-4 min suffers from immense rise in cutting temperature and friction. Thus, it continuously requires effective cooling and lubrication effect for protecting the tool wear. The study reveals that the lowest cutting force and friction coefficient can be achieved by setting a larger spray distance $(35 \mathrm{~mm})$, a higher droplet density $(1.2 \mathrm{~m} / \mathrm{s})$, and a lower gas velocity $(26 \mathrm{~m} / \mathrm{s})$.

\section{CONCLUSIONS}

Droplet spray characteristics of an atomization-based cutting fluid (ACF) system were experimentally and theoretically studied with respect to three ACF spray parameters including droplet and gas velocities, and spray distance. Machining experiments on a titanium alloy, Ti-6Al-4V also are performed in order to understand the effect of the droplet spray behavior on the machining performances, viz., tool life/wear, and surface finish. The following conclusions are drawn from this study:

i) When a high-velocity gas dispenses at in the center in a droplet-gas co-flow jet, the diffusion between the droplets and the gas is fully-developed after a certain distance depending on the ACF spray conditions. The 
fluid droplets are found to be distributed uniformly across the jet flare;

ii) A higher droplet velocity and a smaller gas velocity result in a gradual development of co-flow with a larger droplet entrainment angle and entrainment zone, an early development of the self-similarity state. On the other hand, a smaller droplet velocity and a higher velocity may lead to condensation of the fluid droplets because of a higher droplet density at a comparatively smaller jet radius;

iii) With an increase in spray distance and droplet velocity, and a decrease in gas velocity, the flow is seen to be fully-developed (i.e. self-similar) and the droplets are found to be distributed uniformly across the jet flare. These help in reducing the cutting forces and friction coefficient with an effective cooling and improved lubrication, thereby improving the machining performances, viz., tool life and wear, and surface roughness during turning of Ti-6Al-4V.

\section{ACKNOWLEDGEMENT}

The authors would like to thankfully acknowledge the financial support of the TechSolve, Inc., Cincinnati, $\mathrm{OH}$ for conducting this research.

\section{REFERENCES}

[1] Ezugwu, E.O., Wang, Z.M., 1997, Titanium alloys and their machinability-a review, Journal of Materials Processing Technology, 68: 262-274.

[2] Palanisamy, S., et al., 2009, Effects of coolant pressure on chip formation while turning Ti6Al4V alloy, International Journal of Machine Tools and Manufacture, 49: 739-743.

[3] Hong, S.Y., Ding, Y., 2001, Cooling approaches and cutting temperatures in cryogenic machining of Ti-6Al-4V, International Journal of Machine Tools and Manufacture, 41: 1417-1437.

[4] Venugopal, K.A., et al., 2007, Tool wear in cryogenic turning of Ti-6Al-4V alloy, Cryogenics, 47: 12-18.

[5] Venugopal, K.A., et al., 2007, Growth of tool wear in turning of Ti-6Al-4V alloy under cryogenic cooling, Wear, 262: 1071-1078.

[6] Ezugwu, E.O., et al., 2005, Evaluation of the performance of CBN tools when turning Ti-6Al-4V alloy with high pressure coolant supplies, International Journal of Machine Tools and Manufacture, 45: 1009-1014.

[7] Nandy, A.K., et al., 2009, Some studies on high-pressure cooling in turning of Ti-6Al-4V, International Journal of Machine Tools and Manufacture, 49: 182-198.

[8] Hong, S.Y., et al., 2001, New cooling approach and tool life improvement in cryogenic machining of titanium alloy Ti-6Al-4V, International Journal of Machine Tools and Manufacture, 41: 2245-2260.

[9] Pusavec, F., et al., 2010, Transition to sustainable production-Part I: application on machining technologies, Journal of Cleaner Production, 18: 174-184.
[10] Nath, C., Kapoor, S.G. DeVor, R.E., Srivastava, A.K., Design and evaluation of an atomization-based cutting fluid spray system in turning of titanium alloy, In Proceedings of the NAMRI/SME, Vol. 40, Notre Dame, Indiana, USA, 4-8 June, 2012.

[11] Rukosuyev, M., et al., 2010, Understanding the effects of system parameters of an ultrasonic cutting fluid application system for micromachining, Journal of Manufacturing Processes 12: 92-98.

[12] Rukosuyev, M., Goo, C.S., Jun, M.B.G, Park, S.S., 2010, Design and development of cutting fluid system based on ultrasonic atomization for micro-machining, Transaction of the NAMRI/SME 38: 97-104.

[13] Jun, M.B.G., et al., 2008, An experimental evaluation of an atomization-based cutting fluid application system for micromachining, ASME Transactions - Journal of Manufacturing Science and Engineering, 130: 0311181-8.

[14] Ghai, I., et al., 2010, Droplet behavior on a rotating surface for atomization-based cutting fluid application in micromachining, ASME Transactions, Journal of Manufacturing Science and Engineering 132: 011017-10.

[15] Ghai, I., 2010, Analysis of droplet behavior on a rotating surface in atomization-based cutting fluid systems for micro-machining, MS Thesis, University of Illinois at Urbana-Champaign, Urbana, Illinois, USA.

[16] Ricou, F.P., Spalding, D.B., 1961, Measurements of entrainment by axisymmetrical turbulent jets, Journal of Fluid Mechanics 11: 21-32.

[17]Papadopoulos, G., Pitts, W.M., 1998, Scaling the near-field centerline mixing behavior of axisymmetric turbulent jets 36: $1635-1642$.

[18]Pitts, W.M., 1991, Reynolds number effects on the mixing behavior of axisymmetric turbulent jets, Experiments in Fluids 11: 135-141.

[19] Pitts, W.M., 1991, Effects of global density ratio on the centerline mixing behavior of axisymmetric turbulent jets, Experiments in Fluids 11: 125-134.

[20] Fellouah, H., Ball, C.G., Pollard, A., 2009, Reynolds number effects within the development region of a turbulent round free jet, International Journal of Heat and Mass Transfer 52: 3943-3954.

[21]Parker, R., Rajagopalan, S., Antonia, R.A., 2003, Control of an axisymmetric jet using a passive ring, Experimental Thermal and Fluid Science 27: 545-552.

[22] Rothe, P.H., Block, J.A., 1977, Aerodynamic behavior of liquid sprays, International Journal of Multiphase Flow 3: 263-272.

[23]Lee, S.Y., Tankin, R.S., 1984, Study of liquid spray (water) in a non-condensable environment (air), International Journal of Heat and Mass Transfer 27: 351-361.

[24]Bernoulli's Principle, http://en.wikipedia.org/wiki/ Bernoulli_effect.

[25] Maczyński, J.F.J, 1961, A round jet in an ambient co-axial stream, Journal of Fluid Mechanics 13: 597-608.

[26] Jet flow, http://encyclopedia2.thefreedictionary.com/Jet+ Flow. 